\title{
Synoptic-Scale Variability and Its Relationship with Total Ozone and Antarctic Vortex Displacements
}

\author{
Paula K. Vigliarolo \\ Centro Austral de Investigaciones Científicas, CONICET, Ushuaia, Tierra del Fuego, Argentina \\ CAROLINA S. VERA \\ Centro de Investigaciones del Mar y la Atmósfera, CONICET, and Departamento de Ciencias de la Atmósfera y los Océanos, \\ Universidad de Buenos Aires, Buenos Aires, Argentina \\ SusAna B. DíAZ \\ Centro Austral de Investigaciones Científicas, CONICET, Ushuaia, Tierra del Fuego, Argentina
}

(Manuscript received 8 October 2004, in final form 22 December 2004)

\begin{abstract}
The main synoptic-scale circulation anomaly pattern over extratropical South America during the austral spring (September-November) is identified by means of rotated extended empirical orthogonal function techniques, applied to the meridional wind perturbation time series at $300 \mathrm{hPa}$. The dataset is based on 15 spring seasons (1979-93) of meteorological data from the National Centers for Environmental PredictionDepartment of Energy Atmospheric Model Intercomparison Project version-2 daily averaged reanalyses, given in 17 vertical levels from 1000 to $10 \mathrm{hPa}$. The total-ozone daily measurements for the same period are from the Total Ozone Mapping Spectrometer instrument (version 7). The principal synoptic-scale anomaly pattern is associated with an anticyclone-cyclone pair evolving eastward along subpolar latitudes (and hence it is termed the subpolar mode), with a typical length scale of $5000 \mathrm{~km}$ and a phase velocity of $8 \mathrm{~m} \mathrm{~s}^{-1}$. The subpolar-mode waves, which display the main characteristics of midlatitude baroclinic waves, typically maximize near or above the tropopause and propagate upward into the lower stratosphere, showing large amplitudes even at $50 \mathrm{hPa}$ and above.

Subpolar-mode-related circulation anomalies are found to be responsible for large total-ozone daily fluctuations near southern South America and nearby regions. In the positive phase of the subpolar mode, total-ozone fluctuations, which are negative, adopt a sigmoid structure, with a zonal scale as large as the anticyclone-cyclone pair. Moreover, it is herein shown that the associated anticyclone produces a local ozone-column decrease to the north and east of its center, due to adiabatic uplift of air parcels in the upper troposphere and lower stratosphere. At the same time, the downstream cyclonic disturbance is responsible for large negative total-ozone anomalies to the west and south of its center. As the cyclone develops in the lower stratosphere, it promotes the northward incursion of the Antarctic vortex up to about $55^{\circ} \mathrm{S}$, along with air masses of highly depleted ozone levels.
\end{abstract}

\section{Introduction}

Maximum areas of short time-scale variability are widely known as storm tracks, which are closely related to the preferred track of transient disturbances (of both negative and positive geopotential height perturbation

Corresponding author address: Paula Vigliarolo, CADIC, B. Houssay 200, C. C. 92, (9410) Ushuaia, Tierra del Fuego, Argentina.

E-mail:paulav@ciudad.com.ar centers; Trenberth 1991). The storm-track maximum in the Southern Hemisphere ( $\mathrm{SH})$ is located over the southern Indian Ocean, and a relative minimum is typically found over the eastern South Pacific. Berbery and Vera (1996) showed that during the winter there is also a region of conspicuous high-frequency variability along the subtropical latitudes of the Pacific Ocean. They also showed that baroclinic waves evolve eastward in packets along the storm-track regions, in which downstream baroclinic development is part of their life cycle. During the winter season, storm-track distribu- 
tion in southern South America (SSA) and adjacent oceans presents relative maximum values over both subtropical and midlatitudes. Vera et al. (2002) and Vigliarolo et al. (2001, hereafter VI01), showed that the leading modes of high-frequency variability over this region are characterized by baroclinic wave trains evolving to the east along upper-tropospheric subtropical and subpolar jet latitudes, although subpolar waves propagate faster and exhibit lower wavenumbers than the subtropical waves.

The activity of the transient disturbances in the $\mathrm{SH}$ may vary according to the season, in association with seasonal changes of the mean flow in which they are embedded (Trenberth 1991). While in August the maximum wind speeds are found in relation to polarnight jet maturity state, in October, the jet experiences a conspicuous deceleration due to the progressive warmth of the high-latitude temperatures as the summer approaches. The jet deceleration sets favorable conditions to allow the vertical propagation of waves of intermediate zonal wavenumbers. According to the Charney and Drazin (1961) criterion, total wavenumbers 5 or less at $45^{\circ}$ of latitude are able to propagate vertically with westerlies lower than $15 \mathrm{~m} \mathrm{~s}^{-1}$ (James 1994). In this sense, during winter, subpolar baroclinic waves in the vicinity of SSA maximize close to the tropopause and do not extend much farther than the lowermost stratospheric levels (VI01). On the other hand, at least to our knowledge, there is a lack of literature about the characteristics of the transient variability over SSA in spring. In particular, questions such as the following still need to be answered: (a) Which are the most active synoptic-scale patterns over extratropical South America; (b) What characterizes their temporal variation and structure; and (c) Assuming that they are able to extend significantly upward into the lower stratosphere, what are the possible consequences for the stratospheric variability and ozone?

It is well known that baroclinic waves are characterized by potential vorticity anomalies near the tropopause, which typically decrease the tropopause height in regions of cyclonic vorticity and raise it where the vorticity is of anticyclonic sign (Hoskins et al. 1985, among others). Moreover, potential vorticity highfrequency variability and ozone are also well correlated near the tropopause (e.g., Reed and Danielsen 1959; Vaughan and Price 1991; Salby and Callaghan 1993). Since a great contribution to total-ozone content comes from the lower stratosphere (Salby and Callaghan 1993), the processes that tend to diminish the tropopause height also will tend to replace ozone-poor tropospheric air by ozone-rich stratospheric air, and thus total-ozone content will increase. Therefore, baroclinic wave ridges (troughs) will be associated with enhanced (diminished) total-ozone levels. This mechanism is suitable to explain ozone-column variability due to synoptic activity in regions of smooth mean ozone meridional gradients, as observed at midlatitudes in winter (e.g., VI01, and references therein). Nevertheless, during the SH spring, the ozone meridional gradient experiences a substantial increase south of $50^{\circ} \mathrm{S}$, in association with high-latitude ozone-depleted levels (Figs. 1a,b). Therefore, during this season the relationship between midlatitude baroclinic perturbations and ozone may not develop as simply as described before.

Ozone and weather relationships have been largely investigated through individual case studies (e.g., Orlanski et al. 1989; McKenna et al. 1989; Rood et al. 1992; Orsolini et al. 1995). Mote et al. (1991) for the Northern Hemisphere and VI01 for the SH are some of the few papers that relate baroclinic wave evolution to ozone-column fluctuations during the winter season from a statistical point of view. Nevertheless, up to now there are no such studies for the spring.

Hence, the main objectives of this paper are the following: (i) to characterize high-frequency variability over SSA and adjacent regions during the spring months, and (ii) to address the role that baroclinic waves play in the total-ozone daily distribution in a season of strong mean total-ozone depletion and favored conditions to allow a greater vertical extent of waves. The organization of this paper is as follows: the next section describes datasets and methodology used; in section three, we introduce subpolar-mode main characteristics; while in the fourth and fifth sections we concentrate on ozone-column variations related to subpolar patterns. Finally, in the last section the main results are summarized and discussed.

\section{Data and methodology}

The dataset is based on 15 austral spring seasons (1 September-30 November), spanning from 1979 to 1993 of National Centers for Environmental PredictionDepartment of Energy Atmospheric Model Intercomparison Project version-2 (NCEP-DOE AMIP-II) daily averaged reanalyses (hereafter R-2), given on a regular $2.5^{\circ} \times 2.5^{\circ}$ grid resolution and in 17 vertical levels from 1000 to $10 \mathrm{hPa}$. This period was chosen because during 1979-93 total-ozone global measurements are continuous. The R-2 database is a version that improves upon the widely known NCEP-National Center for Atmospheric Research (NCAR) version-1 reanalyses (hereafter R-1; Kalnay et al. 1996) by fixing some known errors and by updating the parameterizations of the physical processes. The differences between both 
(a) 0ctober Mean 0zone Mixing Ratio

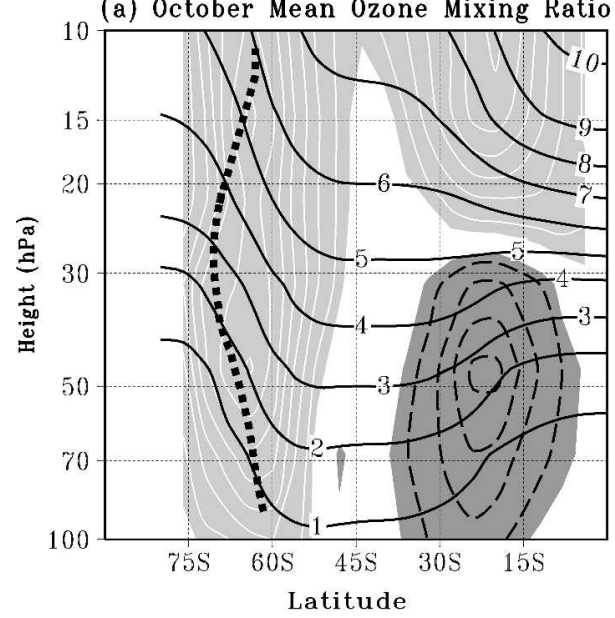

(b) October Mean Total Ozone

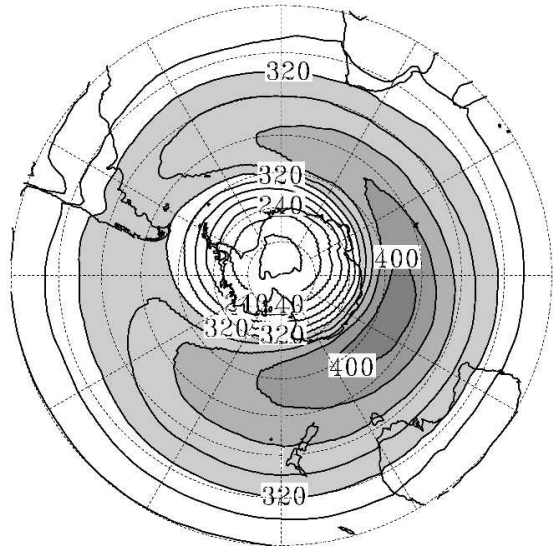

FIG. 1. October mean (a) latitude-height section of ozonemixing ratio derived from the combined measurements of HALOE (in the 1991-97 period, version 19) and MLS (1992-93, version 4) instruments on board UARS (Randel et al. 1998). Contours are drawn every 1 ppmv. Light (heavy) shades represent positive (negative) mean ozone-mixing ratio meridional gradients, with shading intervals drawn every $2 \times 10^{-7} \mathrm{ppmv} \mathrm{m}^{-1}$ (note that shading between -2 and $2 \times 10^{-7}$ ppmv m$^{-1}$ has been omitted). The thick dashed black contour corresponds to the mean position of the boundary of the Antarctic vortex, obtained from linear interpolation of values given in Waugh and Randel (1999). (b) Total-ozone distribution from TOMS version 7 , in the $90^{\circ}-20^{\circ} \mathrm{S}$ latitude band, for the October months of 1979-93. The contour interval corresponds to $20 \mathrm{DU}$, while regions in excess of $320 \mathrm{DU}$ have been shaded.

datasets are referred to in Kanamitsu et al. (2002). In R-2, the misallocation of the Australian Surface Pressure Bogus Data for the Southern Hemisphere (PAOBS), which significantly affected the middle and high latitudes at synoptic time scales, is fixed, suggesting an improvement of daily analyses (Kistler et al. 2001). Nevertheless, R-2 is also subject to errors; perhaps one of the most relevant includes the use of an overturned north-south ozone zonal mean climatology.
Some experiments suggested that this would have a minor impact on the quality of the dataset, despite the introduction of some errors to the radiative fluxes in the stratosphere (Kanamitsu et al. 2002; W. Ebizusaki 2002, personal communication). In this sense, we examined the synoptic-scale anomalous circulation pattern in the lower stratosphere during the austral spring season based on three different datasets: NCEP analyses, R-1, and R-2. We found no significant differences among them, and it is suggested that the ozone climatology misallocation does not affect any of the results from this study.

Daily ozone-column data are from the Total Ozone Mapping Spectrometer (TOMS) instrument, version 7, onboard Nimbus-7 and Meteor-3 satellites for 1979-93 (McPeters et al. 1996); whenever possible, Nimbus-7 data were preferred, especially regarding the overlap period (August 1991-April 1993). The horizontal resolution of total-ozone data is $1^{\circ}$ in latitude and $1.25^{\circ}$ in longitude. October mean ozone-mixing ratio data (Fig. 1a) correspond to the Halogen Occultation Experiment (HALOE), version 19, spanning the 1991-97 period, combined with polar measurements of the Microwave Limb Sounder (MLS) instrument, version 4, with a time period spanning November 1991-April 1993, both onboard the Upper Atmosphere Research Satellite (UARS). Details of the UARS HALOE and MLS ozone-mixing ratio dataset can be found in Fishbein et al. (1996), Park et al. (1996), and Randel et al. (1998).

The 300-hPa meridional wind perturbation time series was utilized to compute the spatial patterns of synoptic-scale waves over extratropical South America. For any grid point and any variable, the perturbation time series (denoted by a "'”) was obtained by removing from the daily average values the corresponding climatological mean seasonal cycle (depicted by the climatological daily averages) and the interannual variability (calculated as the difference between the seasonal mean for each particular year and the climatological seasonal mean). Berbery and Vera (1996) have shown that no further data-filtering procedure is necessary as the meridional wind perturbation defined in that way concentrates most of its variability at synoptic scales. Like so, the calculations presented in this paper are not affected by the decreasing ozone trends observed in the 1980s.

An extended empirical orthogonal function (EEOF; Weare and Nasstrom 1982) technique for four 1-day lag units was applied to the $300-\mathrm{hPa} v^{\prime}$ temporal time series, over a domain enclosed by $80^{\circ}-10^{\circ} \mathrm{S}$ and $130^{\circ}-$ $20^{\circ} \mathrm{W}$. EEOF modes were computed from the correlation matrix. To maximize the local variance within the 
(a) $850 \mathrm{hPa}$ day -1
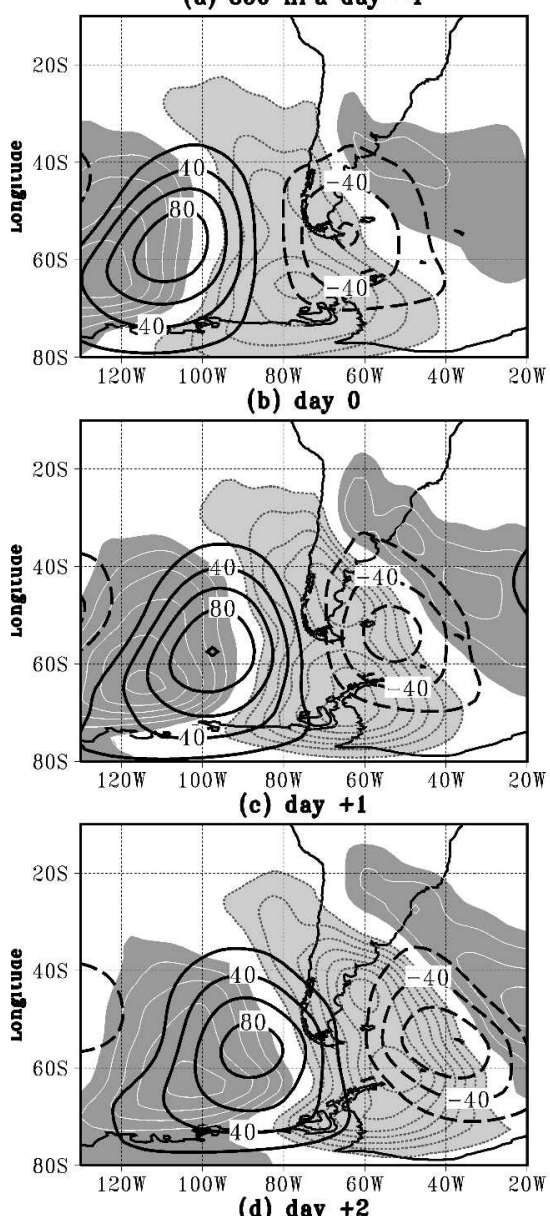

(d) day +2

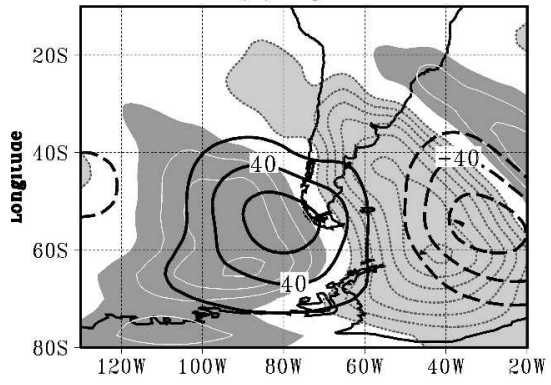

(e) $300 \mathrm{hPa}$ day -1
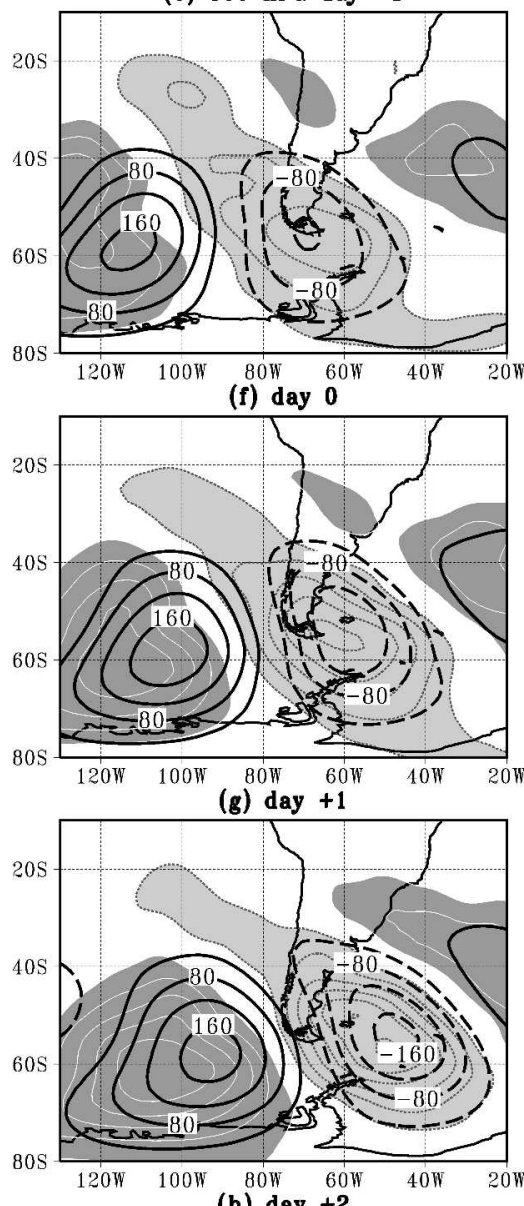

(h) day +2

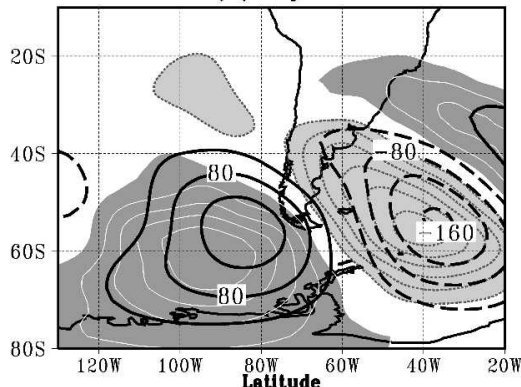

(i) $50 \mathrm{hPa}$ day -1
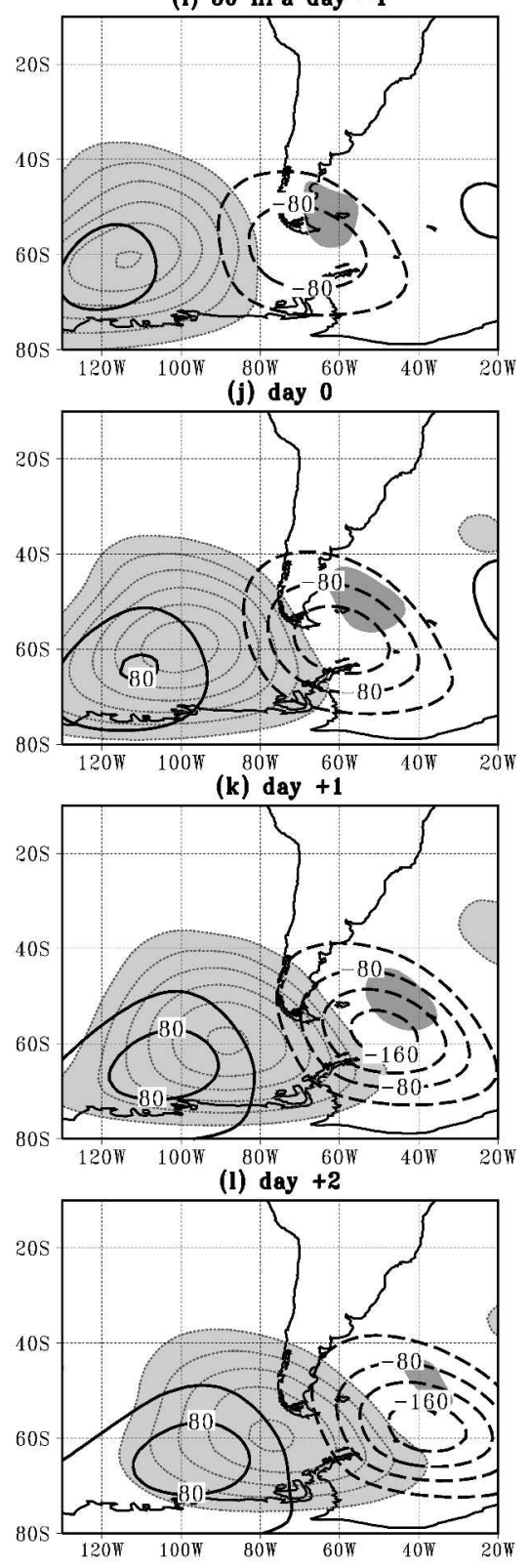

FIG. 2. Positive composites for the subpolar mode, showing the time evolution from day -1 to day +2 of perturbations of geopotential height (contours) and temperature (shaded) at (left) $850 \mathrm{hPa}$, (middle) $300 \mathrm{hPa}$, and (right) $50 \mathrm{hPa}$. Heavy (light) shading represents positive (negative) temperature perturbation regions. Contour intervals are (a)-(d) $20 \mathrm{~m}$ and $0.5 \mathrm{~K}$; (e)-(h) $40 \mathrm{~m}$ and $0.3 \mathrm{~K}$; (i)-(l) 40 $\mathrm{m}$ and $0.5 \mathrm{~K}$, respectively. All 0 contours have been omitted.

domain, the EEOF modes were further rotated using the Varimax method (Horel 1981) and hereafter will be referred to as REEOFs. The choice of the effective number of eigenmodes to be rotated follows O'Lenic and Livezey (1988) criteria.

The principal REEOF modes explain $4.94 \%, 4.26 \%$, $3.64 \%$, and $3.63 \%$ of the total variance, respectively, with each individual variance being about one-fourth of what would be obtained from a traditional EOF analysis (Lau and Chan 1985). First and fourth leading REEOFs constitute a pair of modes that are in quadrature phase shift (and thus represent the propagation of the same local wave). The first REEOF pattern (Fig. 2) was chosen for this study as it better represents the baroclinic waves evolving along mid- and high latitudes over the subpolar jet location, and hence is termed the 
subpolar mode. As documented by VI01, the same REEOF appears as dominant in the winter season, although in spring the centers are displaced about $5^{\circ}-10^{\circ}$ south. Second and third REEOFs describe waves propagating eastward following the Antarctic coast (not shown).

REEOF patterns were also calculated with European Centre for Medium-Range Weather Forecasts daily reanalyses (ERA) at 1200 UTC for the 1979-93 spring seasons. The REEOF factor loadings have similar spatial structure than those calculated with R-2, although those using ERA exhibit somewhat weaker values and thus explain less variance.

Subpolar-mode characteristics and their influence in the total-ozone daily fields are investigated by means of composite maps of relevant variables. Positive composites refer to the 5-day time evolution obtained by averaging daily fields associated with values of REEOF temporal coefficients larger than 0.8 times the standard deviation of the series. Similarly, the negative composites were constructed by taking into account the temporal coefficients of less than -0.8 times the standard deviation of the series. In this sense, 101 (105) cases make up the positive (negative) composite set. The statistical significance at the $5 \%$ level of all composite fields was confirmed using a $t$ test, where we assumed that the degrees of freedom equal one-fifth of the total number of data.

\section{Subpolar mode}

\section{a. Horizontal and vertical structure}

In the following section, only results for subpolarmode positive composites are shown because of the high degree of symmetry with the corresponding negative ones. Figure 2 displays the spatial patterns and temporal evolution of temperature and geopotential height perturbations associated with the subpolar mode. In the lower troposphere $(850 \mathrm{hPa})$, the left column shows the time evolution of an anticyclonic center over the southeast Pacific Ocean, and a cyclonic one just over SSA. The wave pattern has a characteristic length scale of about $5000 \mathrm{~km}$ (zonal wavenumber 4-5) and a phase speed of $8 \mathrm{~m} \mathrm{~s}^{-1}$. The center trajectories are mainly zonal and along $55^{\circ} \mathrm{S}$ over the Pacific Ocean, but once on the lee side of the Andes they detour to the northeast. Although SSA is a region in which meridional wave propagation is possible (Ambrizzi et al. 1995), such behavior could be also promoted by the interaction between transient perturbations and the orography (Gan and Rao 1994). Vera et al. (2002) showed that near the Andes, the lower-tropospheric portion of the synoptic wave tends to advance following the shape of the terrain, while exhibiting an equatorward migration on the lee side. This behavior is suggested in the evolution of the anticyclonic center from day +1 to day +2 (Figs. $2 \mathrm{c}, \mathrm{d})$.

Both the horizontal and vertical structure of the waves associated with the subpolar mode (Figs. 2, 3) display the main characteristics of midlatitude baroclinic waves (Lim and Wallace 1991). These are summarized as follows. (i) The anomalous temperature pattern peaks both at low-tropospheric and low-stratospheric levels (Figs. 2a-d, 2i-1, 3b), while it exhibits a sign change at the tropopause level (Figs. 2e-1, 3b). (ii) The geopotential height perturbation centers are tilted southwestward with altitude, while the temperature perturbation centers are tilted eastward (Figs. 2, 3b); this configuration is favorable for developing baroclinic waves through the intensification of poleward heat fluxes (Figs. 3b,c). (iii) The progressive upward increase of the geopotential height perturbation amplitudes to the east strongly suggests a vertical dispersion of energy (Fig. 3a; Lim and Wallace 1991).

A comparison between the waves associated with subpolar mode and those typical of the extratropical South American region during the austral winter season (VI01; Vera et al. 2002) show that they share essentially the same characteristics, although the latter are more affected by the presence of the Andes, which produces a strong modification of the wave structure at low levels. In addition, the spring subpolar waves attain their extremes at higher altitudes compared to their winter counterparts, extending far above the tropopause with prominent amplitudes in the lower stratosphere (Figs. 2i-1, 3a). Moreover, across the tropopause, they undergo a noticeable change in their horizontal structure, mainly through a lowering of their zonal wavenumber from 4-5 in the troposphere to 3-4 in the lower stratosphere (Fig. 2, left and middle columns, respectively). At $50 \mathrm{hPa}$, while the stratospheric portion of the cyclone is located just over or only a few degrees to the west of its upper-tropospheric counterpart, the anticyclone over the South Pacific displays, in contrast, a conspicuous shift to the southwest of about $10^{\circ}$ (Fig. 2, middle and right columns).

\section{b. Vertical propagation of the synoptic signal}

The vertical structure of the vertical component of the energy flux (Fv) associated with subpolar mode has been considered as well (Fig. 3d). Following Orlanski and Sheldon (1993), the expression for Fv flux is

$$
\mathrm{Fv}=\overline{\rho \omega^{\prime} \phi^{\prime}}
$$



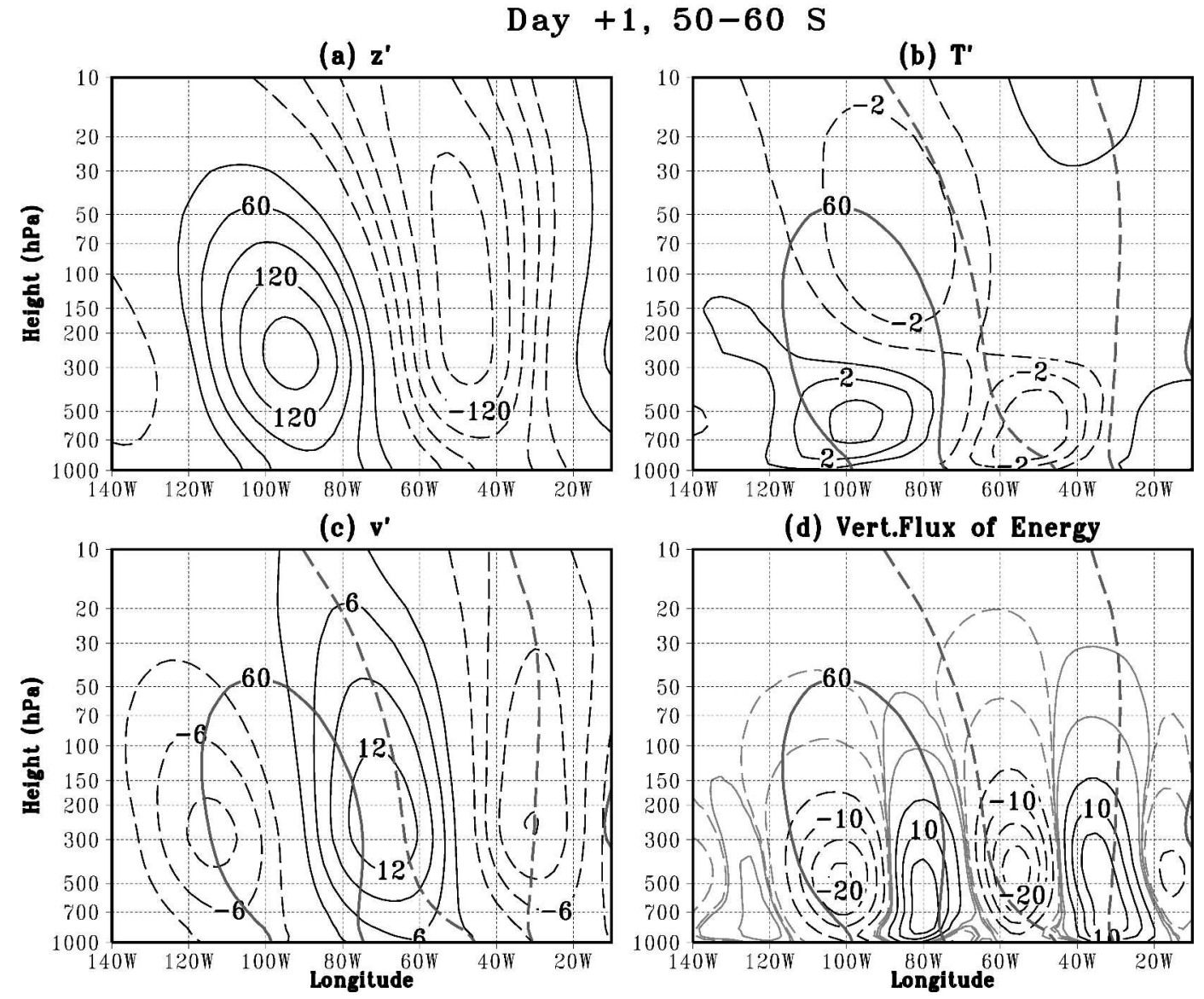

FIG. 3. Longitude-height positive composites for the subpolar mode of the following perturbation fields: (a) geopotential height, (b) temperature, and (c) meridional wind. Also shown is (d) the vertical component of the energy flux associated with the wave. All quantities are displayed for day +1 and averaged over the $60^{\circ}-50^{\circ} \mathrm{S}$ latitude band. Contour intervals are (a) $30 \mathrm{~m}$, (b) $1 \mathrm{~K}$, (c) $3 \mathrm{~m} \mathrm{~s}^{-1}$, and (d) $5 \times 10^{-2} \mathrm{~Pa} \mathrm{~m}^{2} \mathrm{~s}^{-3}$ (light gray contours correspond to \pm 0.001 and $\pm 0.1 \mathrm{~Pa} \mathrm{~m}^{2} \mathrm{~s}^{-3}$ ). In all panels both the -60 and the $+60 \mathrm{~m}$ geopotential height perturbation contours are shown for reference (thick dashed and solid lines, respectively). All 0 contours have been omitted.

where $\rho$ stands for the density, $\omega^{\prime}$ and $\phi^{\prime}$ are the vertical velocity and geopotential perturbations, respectively, and the overbar represents the composite of cases for the subpolar mode. From Fig. 3d, it can be seen that maximum Fv fluxes are found at midtropospheric levels, with absolute values rounding $0.2 \mathrm{~Pa} \mathrm{~m}^{2} \mathrm{~s}^{-3}$. In addition, Fv fluxes extend well above the tropopause, indicating that the eddy energy is flowing upward at the leading fringe of both the cyclonic and anticyclonic perturbations (where the sign is negative), from the surface to the lower stratosphere. Chang and Orlanski (1994) have shown that Fv divided by the energy represents a good approximation to the group velocity of wave packets, even if they are linear or not. Hence, Fig. 3d also suggests that the synoptic signal is propagating from the troposphere to the lower stratosphere, contributing to the growth of the waves above the tropo- pause. In this sense, we examined Hovmöller diagrams of composites of geopotential height perturbation averaged in $55^{\circ}-70^{\circ} \mathrm{S}$ for the subpolar-mode extreme events (Fig. 4). An extreme event is defined when the absolute value of the subpolar-mode time series coefficient is larger than 1.8 times the standard deviation. Using this criterion, 29 statistically significant events were found for positive composites. However, it should be noted that considering all the cases that make up the positive composite set (101, with the extreme cases also included) provided almost identical results, although with lower amplitudes. By day +1 , the main cyclonic disturbance at $300 \mathrm{hPa}$ minimizes to $-210 \mathrm{~m}$ slightly east of $60^{\circ} \mathrm{W}$ (Fig. 4b, left and right panels), while it attains a minimum in the lower stratosphere one day after $\left(-240 \mathrm{~m}\right.$ near $\left.40^{\circ} \mathrm{W}\right)$, supporting the notion of upward propagation of the synoptic wave signal. The 

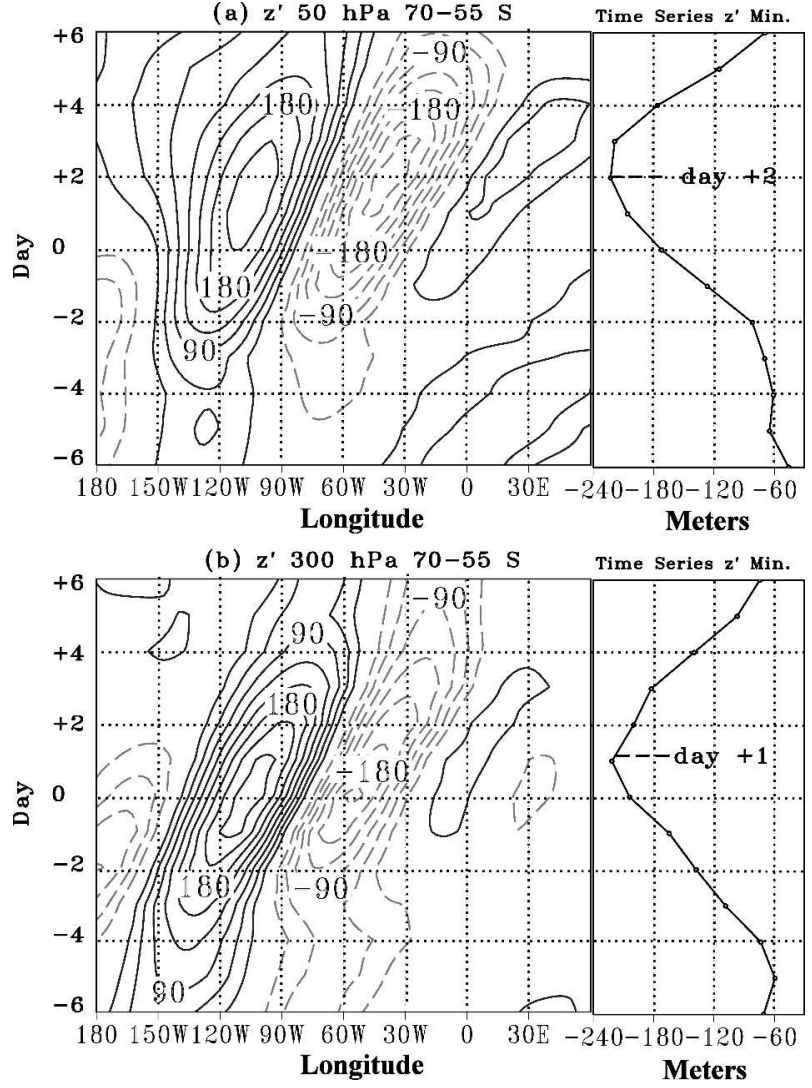

FIG. 4. (left) Hovmöller diagrams of positive composites for the subpolar mode of geopotential height perturbations. Composites correspond to the extreme events (see text); $z^{\prime}$ has been averaged over $55^{\circ}-70^{\circ} \mathrm{S}$, and is shown for (a) 50 and (b) $300 \mathrm{hPa}$. The time evolution starts on day -6 and ends on day +6 . Contour interval is $30 \mathrm{~m}$ and 0 contours have been omitted. (right) Time series of geopotential height perturbation minimum associated with the main cyclonic disturbance at 50 and $300 \mathrm{hPa}$; units are in $\mathrm{m}$.

same behavior is observed for the anticyclone, which the lower-stratospheric portion maximizes about 1 or 2 days after its upper-tropospheric counterpart.

According to Haynes and Shuckburgh (2000), the lowest boundary of the Antarctic polar vortex lays close to $400 \mathrm{~K}(\sim 100-120 \mathrm{hPa})$. Subpolar waves exhibiting large amplitudes at altitudes that concur with the lower vortex region has important implications for the Antarctic vortex dynamics and will be discussed in subsequent sections.

\section{Total-ozone composites}

In this section, the focus is on the analysis of composites for subpolar pattern of total ozone and its relationship with atmospheric fields. As mentioned in section 2, the 5-day time evolution depicted in Fig. 5 was obtained by averaging daily total-ozone perturbation

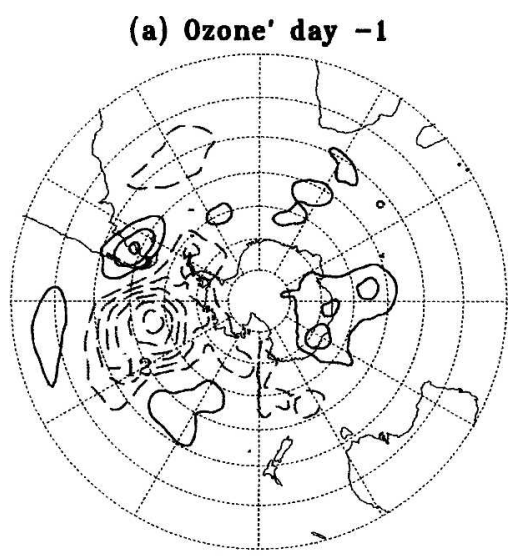

(b) day 0

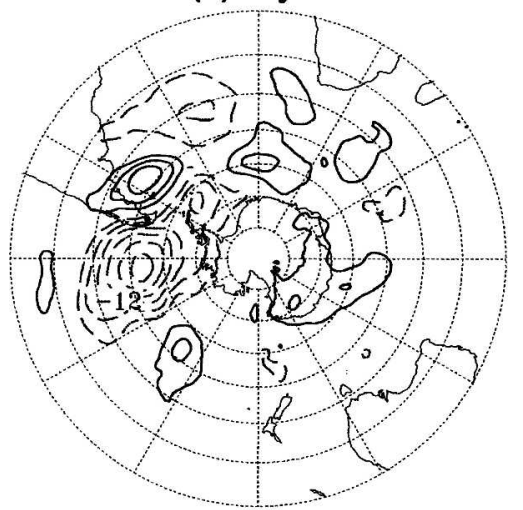

(c) day +1

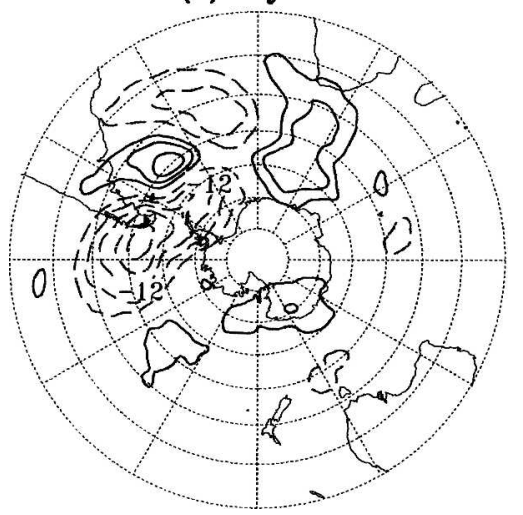

FIG. 5. Positive composites for the subpolar mode of ozone perturbations in the $90^{\circ}-20^{\circ} \mathrm{S}$ latitude band, from (a)-(c) day -1 to day +1 Contour intervals correspond to 4 DU with the 0 contour omitted.

fields over those days in which the REEOF temporal coefficients are larger than 0.8 times the standard deviation of the series. Figures $5 \mathrm{a}-\mathrm{c}$ display the evolution of ozone-column perturbations from day -1 to day +1 , when since the beginning of the sequence, a negative center is found near $57^{\circ} \mathrm{S}, 100^{\circ} \mathrm{W}$ and a positive one is developing over the Patagonian region. By day 0 (Fig. $5 b)$, the negative total-ozone perturbation minimizes to 


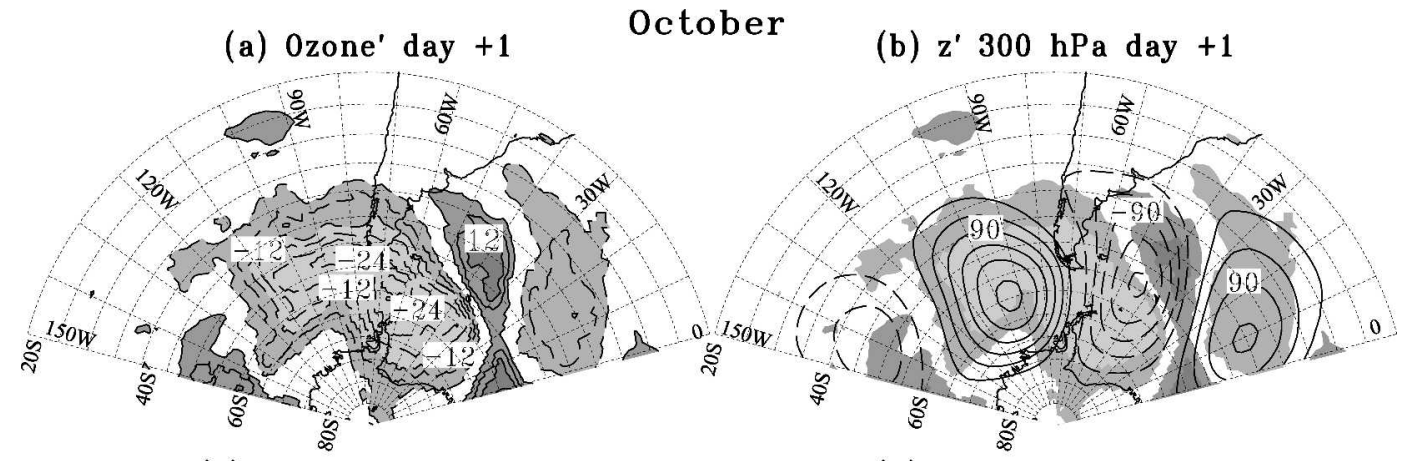

(c) $\mathrm{z}^{\prime} 50 \mathrm{hPa}$ day +1

(d) T' $150 \mathrm{hPa}$ day +1

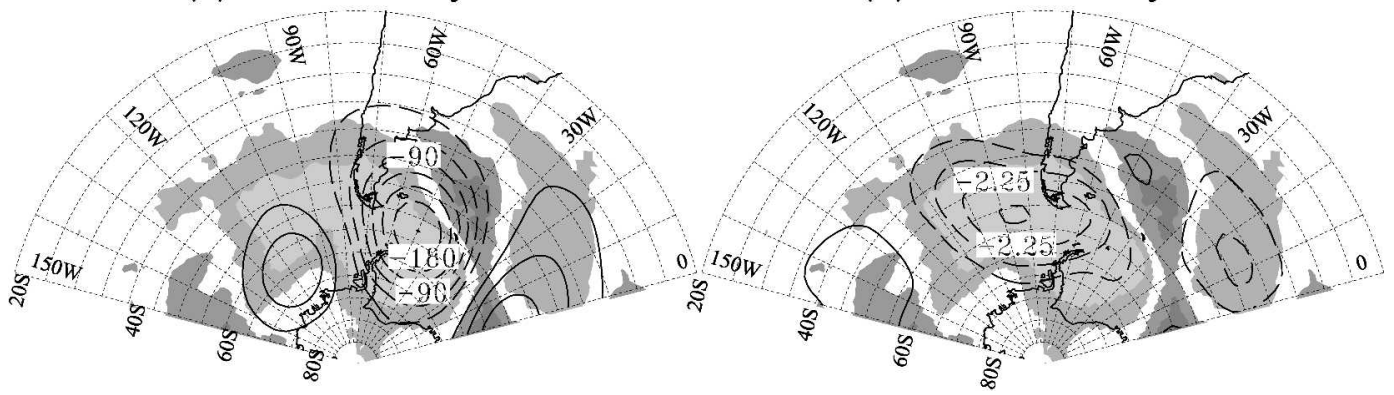

FIG. 6. October (positive) composites for the subpolar mode of perturbations of (a) ozone, (b) geopotential height at $300 \mathrm{hPa}$, (c) geopotential height at $50 \mathrm{hPa}$, and (d) temperature at $150 \mathrm{hPa}$. All perturbation fields are shown for day +1 . Contour intervals correspond to (a) $4 \mathrm{DU}$; (b), (c) $30 \mathrm{~m}$; and (d) $0.75 \mathrm{~K}$ with 0 contours omitted. In (b)-(d), light (heavy) gray shading represents negative (positive) ozone perturbation values.

-26 Dobson units (DU) slightly west of $90^{\circ} \mathrm{W}$, while the positive center also attaches a maximum of $16 \mathrm{DU}$ off the coast of Argentina. These perturbation values are comparable to those observed for winter total-ozone disturbances over the same region (VI01). Also during day 0 , a southeastward extension of the negative ozone center becomes apparent, extending well beyond the Antarctic Peninsula to the east and getting deeper the day after (Fig. 5c).

When considering individual spring months, we found that the positive composites for the subpolar mode of total-ozone perturbations display the largest amounts in October. Total-ozone perturbation composites for October, which include 34 cases (which represents about one-third of the total number of cases for the whole spring), show larger disturbances though they have almost the same pattern (cf. Fig. 6a with Fig. $5 c)$. Hence, in what follows, discussion will be centered on the October positive composites for the subpolar mode.

By day +1 (Fig. 6a), the October ozone-column negative perturbations near SSA display a conspicuous southeastward lengthening, and the whole pattern resembles a sigmoid feature, with the upper branch lying over the southeastern Pacific and the bottom branch over the Weddell Sea. This feature in the total-ozone perturbation field is in contrast with what is observed during the winter, when total-ozone perturbations typically display shorter zonal scales (cf. Fig. 6a with Figs. 7 and 9 from VI01).

October composites of geopotential height perturbations at day +1 are shown as well (Figs. 6b,c) and should be compared with the composites for the whole spring months (Figs. 2g,k). At $300 \mathrm{hPa}$, ozone-column negative perturbations lying over the southeastern $\mathrm{Pa}$ cific Ocean (light-gray-shaded regions in Fig. 6b) are associated, north of $65^{\circ} \mathrm{S}$, with the anticyclonic center, while negative total-ozone values to the south of SSA and east of the Antarctic Peninsula are in relation to the western and southern portion of the cyclone downstream. While typically during spring geopotential height zonal wavenumbers 4-7 correlate negatively with ozone at the troposphere level over midlatitudes, south of $60^{\circ} \mathrm{S}$, such correlation turns out to be positive and maximum over $\sim 50-20 \mathrm{hPa}$ (Stanford et al. 1995), near the region where ozone partial pressure maximizes during that season. The positive correlation between ozone and geopotential height is not only due to synoptic disturbances but is also attributed to the presence of planetary waves very typical of the spring stratosphere (Wirth 1993).

Composites of $150-\mathrm{hPa}$ temperature perturbations 
during day +1 (Fig. 6d), show a pattern of remarkable correspondence with the negative total-ozone center, particularly to the north of $65^{\circ} \mathrm{S}$, suggesting a high and positive correlation. This is in agreement with the results of Ziemke et al. (1997), who noted that ozone and temperature correlation remains positive above the tropopause almost all year round, with extremes near $100 \mathrm{hPa}$ and over the $60^{\circ}-40^{\circ} \mathrm{S}$ latitude band. Nevertheless, southward of $65^{\circ} \mathrm{S}$, the ozone-temperature correlation diminishes, particularly regarding the polar side of the ozone negative center. The ratio between total ozone and $150-\mathrm{hPa}$ temperature perturbations was of the order of $11 \mathrm{DU} \mathrm{K}^{-1}$; while slightly larger, this value compares with the range of ratios 6-10 $\mathrm{DU} \mathrm{K}^{-1}$, resulting if total-ozone fluctuations are only forced by dynamics (Ziemke et al. 1997; Randel and Cobb 1994).

Ozone-column and temperature correlation is associated with both distributions of ozone-mixing ratio and potential temperature in the lower and midstratosphere. According to Wirth (1991), the highly positive correlation follows from the fact that surfaces of potential temperature and ozone-mixing ratio are approximately parallel, a situation that is observed for October at midlatitudes between 100 and $20 \mathrm{hPa}$ (not shown). This would imply that lower-stratospheric temperature perturbations due to the dynamics of synoptic waves could be used as proxies to infer the behavior of the total-ozone anomalies in the region. On the other hand, south of $65^{\circ}-60^{\circ} \mathrm{S}$ ozone-mixing ratio surfaces undergo an abrupt upward migration in relation to high-latitude low-ozone content (Fig. 1a), with the result that they are no longer congruent with potential temperature surfaces; this explains why ozone and temperature correlation diminishes over that region.

\section{Potential vorticity outlook}

Potential vorticity on isentropic coordinates (hereafter PV), which is negative in the $\mathrm{SH}$, is associated with upper-tropospheric synoptic disturbances (Orlanski and Katzfey 1991). Areas with minimum PV are typically found along with air masses with cyclonic (negative) relative vorticity in pressure coordinates, while negative but with locally higher PV amounts are associated with the presence of an anticyclone. Furthermore, the PV field also experiences a conspicuous variation with latitude and height, with minimum values at polar latitudes and higher stratospheric levels, due to the static stability parameter that dominates over the absolute vorticity distribution. Therefore, within one isentropic level above the tropopause, regions with significant negative PV may be suggesting the presence of air masses from higher in the stratosphere.
Figure 7 shows October composites for the subpolar mode of $\mathrm{PV}$, both at the $360-\mathrm{K}$ isentropic level (which corresponds to approximately $170 \mathrm{hPa}$ at midlatitudes) and at $490 \mathrm{~K}(\sim 60 \mathrm{hPa})$. By day -2 in the lowest stratosphere (Fig. 7a), the local maximum of PV over $35^{\circ}-$ $55^{\circ} \mathrm{S}, 120^{\circ}-100^{\circ} \mathrm{W}$ denotes the presence of the anticyclonic perturbation. Immediately downstream, a tongue of PV minimum values along $80^{\circ} \mathrm{W}$ corresponds to the location of the cyclonic disturbance. Two days later (Fig. 7b), the trough intensifies and experiences a meridional elongation off the east coast of Patagonia, reaching a peak value of -13 PVU over the Weddell Sea, in agreement with the cyclonic behavior depicted in Fig. 6b.

It is well known that ozone and PV are highly correlated fields in the lower stratosphere (Vaughan and Price 1991; Salby and Callaghan 1993; among others); in this sense, composites of total-ozone have been considered as well and are shown as shaded regions in Fig. 7. During lag -2 (top panels of Fig. 7), the total-ozone field displays minimum values from the south of the Antarctic Peninsula through midlatitudes of the southwestern Pacific Ocean, with a clear NW-SE direction. At $360 \mathrm{~K}$ (Fig. 7a), the total-ozone configuration is associated, in its northwestern extreme with the PV ridge, while its southeast section concurs with the location of the PV trough, with the axis of minimum total ozone being across the PV gradient. By day +1 (Fig. 7b), an overall decrease in total-ozone levels is observed over $45^{\circ}-60^{\circ} \mathrm{S}, 100^{\circ}-70^{\circ} \mathrm{W}$, in the southeast Pacific, and from central Patagonia to the Weddell Sea, which reflects the sigmoid feature of ozone-column negative anomalies (Fig. 6a).

The occurrence of the total-ozone minimum in relation to the presence of the Pacific anticyclone could be understood as follows. In the midlatitude lower stratosphere, the ozone-mixing ratio is nearly conserved following the motion for time scales of 1 or 2 weeks (Solomon and García 1985; Salby and Callaghan 1993; among others). Moreover, also in this atmospheric section for synoptic time scales, the flow could be considered adiabatic and frictionless, leading to PV conservation (Andrews et al. 1987). When air parcels approach the PV ridge, they typically experience uplift, adiabatic expansion, and cooling, which in turn leads to a decrease of its ozone number density in the lower stratosphere (Perez et al. 2000).

To examine the climatological characteristics of both polar stratospheric vortices, Waugh and Randel (1999) utilized the elliptical diagnosis applied to PV data, which enables us to define some useful vortex parameters as well as to quantify their structure and evolution. In this sense, the Antarctic vortex boundary 


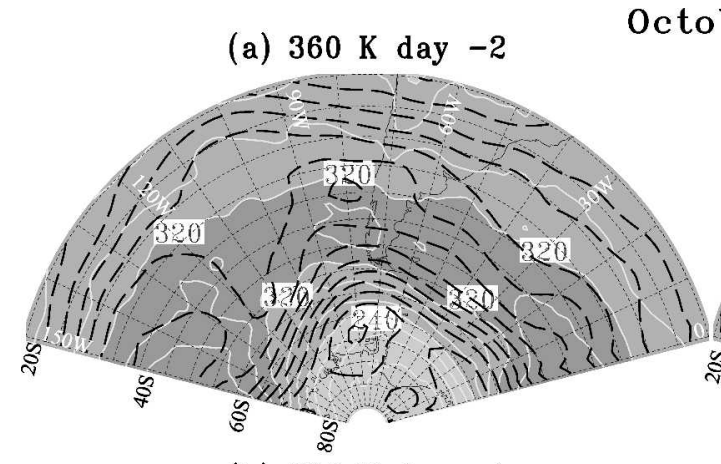

October

(b) $360 \mathrm{~K}$ day +1
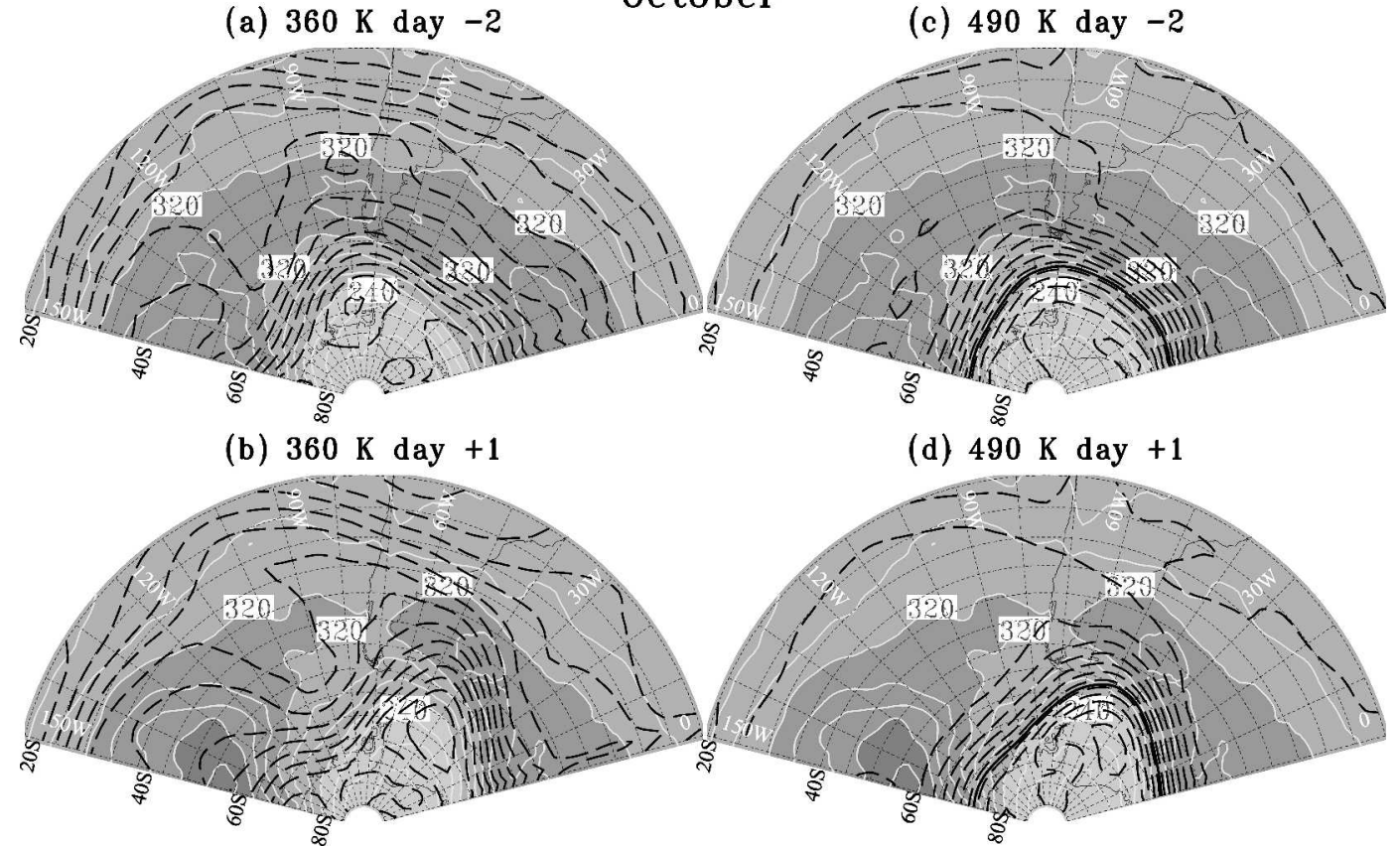

FIG. 7. October (positive) composites for the subpolar mode of potential vorticity at (left) 360 and (right) $490 \mathrm{~K}$, during (top) day -2 and (bottom) day +1 , contoured (a), (b) every 1 PVU from -1 to -13 PVU and (c), (d) every 5 PVU from -15 to -75 PVU. At $490 \mathrm{~K}$, the location of the vortex boundary is shown in thick solid black contour (see text). In all panels, shaded areas represent corresponding total-ozone composites, with a shading interval of 20 DU.

shown throughout was calculated first considering the "modified" PV contours used by those authors to define the vortex edge, then converted to "real" PV values, and, last, interpolated onto the isentropic levels used in this study. At $490 \mathrm{~K}$ (right panels, Fig. 7), the -53 PVU contour denotes the vortex edge (note that the vortex boundary defined in that way also lies close to the maximum gradient of $\mathrm{PV}$ ), with strongly negative $\mathrm{PV}$ inside the vortex. By day +1 , the intensification of the trough at $490 \mathrm{~K}$ seems to promote the northward displacement of the lower stratospheric vortex to the east of SSA (Fig. 7d). As the mean position of the vortex boundary roughly coincides with the maximum mean ozone-mixing ratio meridional gradient up to about 30-40 hPa (Fig. 1a), an equatorward displacement of the lower-stratospheric vortex could bring about highly ozone-depleted air masses. In the subpolar composites, the lower portion of the vortex is able to reach $55^{\circ} \mathrm{S}$ over the southwestern Atlantic, and the associated low total-ozone levels are evident (Fig. 7d). In agreement, Perez et al. (2000) reported two episodes of reduced ozone levels over SSA caused by the advance of the low-stratospheric Antarctic vortex over that region.

Figure 8 displays longitude- and latitude-height sections in isentropic coordinates for both $\mathrm{PV}$ and $\mathrm{PV}$ perturbation composites. The longitude-height section, at $60^{\circ} \mathrm{S}$ (Fig. 8a), shows that by day +1 , total-ozone negative perturbation extends from $120^{\circ} \mathrm{W}$ to the date line (as seen by comparison with Fig. 6a) with the minimum over $60^{\circ} \mathrm{W}$, slightly on the cyclonic side of the baroclinic wave couplet. As mentioned before, to the west (and north) the ozone-column negative anomalies are related to the anticyclone over $100^{\circ}-80^{\circ} \mathrm{W}$, with positive anomalies of PV from 380 to $600 \mathrm{~K}$. In addition, in the downstream side, negative PV anomalies coincide with the downward displaced PV surfaces, with minimum values of both $\mathrm{PV}$ and $\mathrm{PV}^{\prime}$ inside the vortex area (Fig. 8a). The large negative values of PV anomalies relate to the cyclonic disturbance, which displays large amplitudes even up to $550 \mathrm{~K}(\sim 40 \mathrm{hPa})$ as observed in Fig. 3a. Hence, the cyclonic development is associated with the equatorward penetration of the low-stratospheric vortex, which in turn brings about high-latitude depleted ozone, as seen from the presence of total-ozone negative anomalies from about $70^{\circ} \mathrm{W}$ eastward to $0^{\circ}$. A latitude-height perspective along $50^{\circ} \mathrm{W}$ (Fig. 8b) shows that the minimum PV values at high latitudes remain inside the vortex, while the vortex boundary is located along the axis of minimum PV anomalies. Furthermore, in the lower stratosphere, the meridional advance of the vortex north of $55^{\circ} \mathrm{S}$ becomes evident, in agreement with Fig. 7 d. In this cross section, the ozone-column 
(a) $60 \mathrm{~S}$ day +1

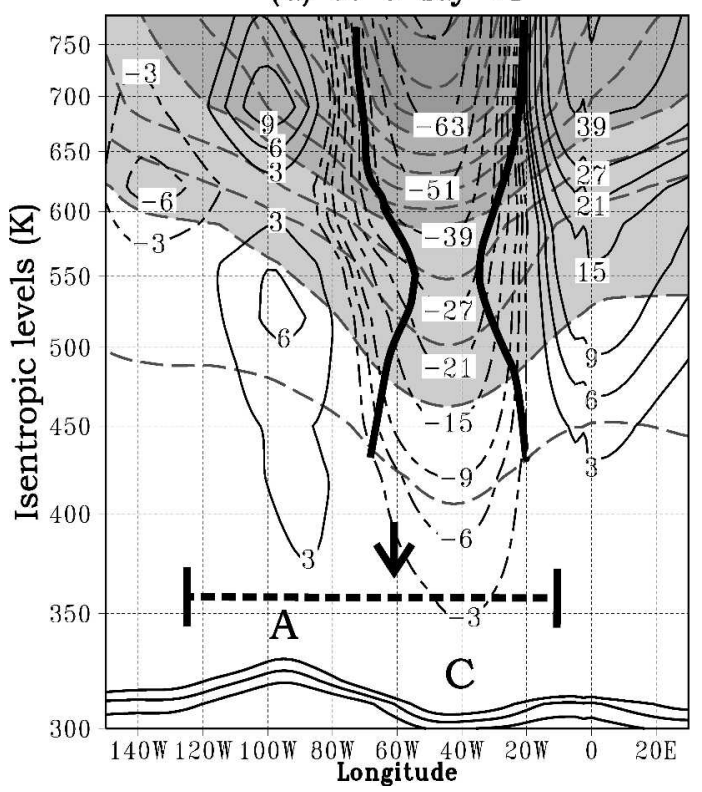

(b) $50 \mathrm{~W}$ day +1

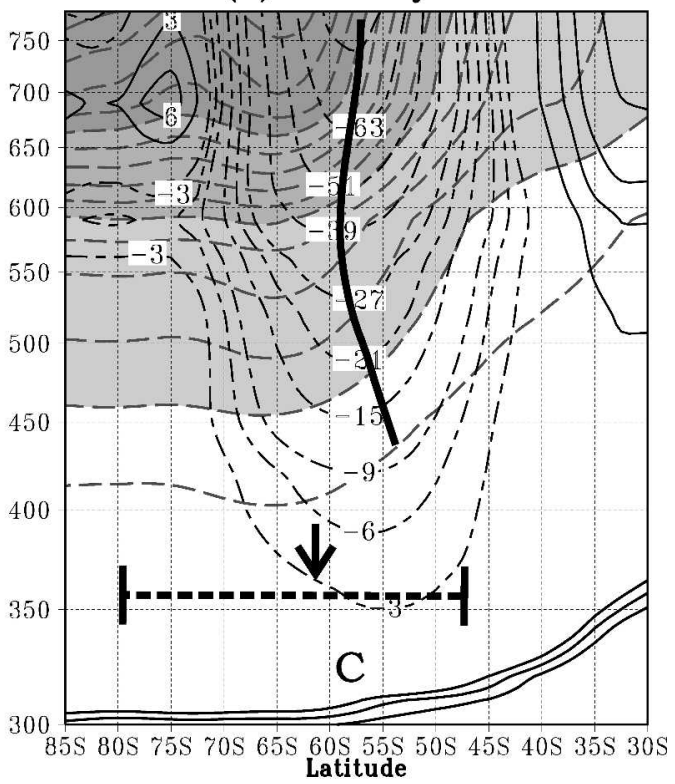

FIG. 8. (a) Longitude-height cross section at $60^{\circ} \mathrm{S}$, in isentropic coordinates, of October (positive) composites for the subpolar mode of potential vorticity perturbation (heavy black contours) and potential vorticity (light gray contours and gray shading), during day +1 . (b) As in (a), but for the latitude-height cross section at $50^{\circ} \mathrm{W}$. The PV contour interval corresponds to $25 \mathrm{PVU}$ (drawn from -25 to -375 PVU). For clarity, only selected PV contours are shown, ranging from -3 to $-75 \mathrm{PVU}$. The thickest black solid contours designate the location of the vortex boundary. Continuous black contours near the bottom of the panels denote the approximate position of the tropopause, as given by the $-2.5,-2$, and -1.5 PVU contours (James 1994). Capital letters indicate the location of the anticyclonic (A) and cyclonic (C) disturbances. Horizontal thick dashed lines near $350 \mathrm{~K}$ stand for the approximate extension of the ozone negative perturbation (see Fig. 6a), and the arrows point out the location of the ozone minimum during that day.

minimum is found somewhat southward of $60^{\circ} \mathrm{S}$, inside the vortex area.

\section{Discussion and conclusions}

A statistical-dynamical diagnosis of the highfrequency variability over SSA and adjacent regions during the austral spring is presented in this paper, as well as a discussion about the role such baroclinic waves play in the total-ozone daily distribution.

Main patterns of synoptic-scale variability were identified by means of REEOFs techniques applied to the 300-hPa meridional wind perturbation time series, over a domain enclosed by $80^{\circ}-10^{\circ} \mathrm{S}$ and $130^{\circ}-20^{\circ} \mathrm{W}$. The first REEOF describes a wave train that propagates to the east along upper-tropospheric subpolar jet latitudes $\left(55^{\circ}-60^{\circ} \mathrm{S}\right)$ and hence is termed the subpolar mode. Composites for the subpolar mode (based on subpolarmode temporal coefficients larger than a threshold) show the typical structure of midlatitude baroclinic waves. The waves, which maximize in the upper troposphere and lower stratosphere, display significant amplitudes up to about $40 \mathrm{hPa}$.
The temporal evolution of the composite waves showed that they reach maximum amplitude first in the upper troposphere and 1-2 days later in the lower stratosphere. This fact, together with the corresponding energy flux pattern, suggests an upward propagation of the synoptic signal from the troposphere (where the waves originate) deep into the lower stratosphere.

Although winter and spring subpolar modes (as analyzed in VI01 and in this paper, respectively) display most of the same characteristics of midlatitude baroclinic waves, only during spring are baroclinic waves able to extend upward into the lower stratosphere. In that region, they could further influence the dynamics of the lower-stratospheric polar vortex, promoting its meridional lengthening over SSA. Therefore, in this transition season the relationship between baroclinic waves and ozone seems not to be as direct as that observed during winter. The analysis of October composites for the subpolar mode (which is the month that displays the largest total-ozone anomalies among the other spring ones) reveals that ozone-column negative fluctuations are related to the location of an anticyclone-cyclone system near SSA. The basic features of 


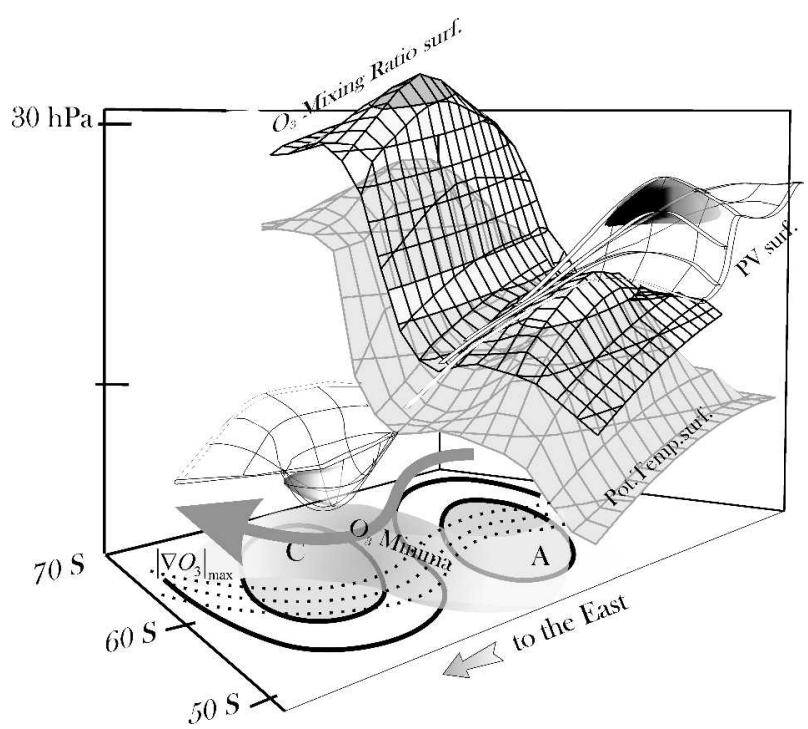

FIG. 9. Idealized scheme about relationships between a midlatitude synoptic wave and ozone perturbations during the SH spring season. North of $65^{\circ} \mathrm{S}$, the anticyclone (A) is accompanied by upward-bended PV surfaces (in light gray contours); also the isentropes are displaced upward in the anticyclonic vicinity, thus indicating that temperature anomalies are negative there. As air parcels approach the anticyclone, they ascend adiabatically, get cooled, and its ozone number density decreases, indicating that ozone-mixing ratio surfaces (drawn in thick solid black contours) also ascend in the region; note that at midlatitudes, ozone-mixing ratio and potential temperature surfaces are approximately parallel, thus explaining the highly positive correlation between these two. Therefore, in the northeast portion of the anticyclone, ozone is observed to diminish. On the other hand, south of $65^{\circ}-60^{\circ} \mathrm{S}$, the downstream cyclone $(\mathrm{C})$ concurs with anomalously negative PV values and is associated with the northward intrusion of the lowerstratospheric vortex (denoted by the thick gray arrow). Inside the vortex, ozone-mixing ratio surfaces typically slope abruptly upward (thus denoting the presence of highly depleted ozone levels), while the vortex boundary is nearly coincident with the horizontal projection of the maximum ozone gradient. As a consequence, in the southeast extreme of the cyclone, ozone anomalies also result in a negative sign. Overall, ozone perturbations adopt a sigmoid distribution, with the minimum lying between the geopotential height centers.

the aforementioned relationship are summarized in Fig. 9 as follows.

North of $65^{\circ} \mathrm{S}$, the development of the anticyclonic perturbation center in the lower stratosphere is accompanied by both upward-sloped surfaces of potential temperature and potential vorticity. As air parcels moving along isentropes approach the anticyclone, they experience uplift, adiabatic expansion, and a decrease of their ozone number density-resulting in the lifting of the ozone-mixing ratio isopleths above the anticyclone. As a result, total-ozone anomalies become negative over the northwestern portion of the anticyclone. It is noteworthy that the same mechanism has been pro- posed to account for total-ozone fluctuations in relation to baroclinic waves during winter, as discussed by VI01 and references therein.

Meanwhile downstream, the outstanding cyclonic development throughout the upper troposphere and lower stratosphere is accompanied by strongly negative PV amounts, indicating the meridional advance of the lower-stratospheric vortex. This also brings about highly depleted ozone-column levels, as across the vortex boundary and inside, ozone-mixing ratio surfaces slope abruptly upward. Therefore, negative total-ozone perturbations are generated over the southeastern section of the cyclone. In conclusion, the entire configuration for the total-ozone anomalies appears as a sigmoid pattern, with a minimum between the anticyclone and cyclonic centers.

The results presented in this paper show the prominent role of spring midlatitude baroclinic waves in driving total-ozone changes. In this sense, taking into account the record low-ozone mean levels in recent years, one could speculate with the possibility of the referred waves to promote the incursion of the ozone hole into permanently inhabited areas of SSA, a topic that is currently being researched.

Acknowledgments. This work was partially supported by UBA (X072, X262), ANPCyT (PICT-99-76355), and IAI-CRN 55. NCEP-NCAR analyses and reanalyses were made available through the Climate Diagnostics Center (http://www.cdc.noaa.gov); UARS HALOE and MLS ozone-mixing ratio data are from W. Randel's reference climatologies at the Sparc Data Center (http://www.sparc.sunysb.edu). The authors thank the two anonymous reviewers for the suggested changes that helped improve the manuscript. This work is part of the Ph.D. dissertation of P. K. Vigliarolo at the University of Buenos Aires.

\section{REFERENCES}

Ambrizzi, T., B. J. Hoskins, and H.-H. Hsu, 1995: Rossby wave propagation and teleconnection patterns in the austral winter. J. Atmos. Sci., 52, 3661-3672.

Andrews, D. G., J. R. Holton, and C. B. Leovy, 1987: Middle Atmosphere Dynamics. International Geophysics Series, Vol. 40, Academic Press, 489 pp.

Berbery, H., and C. Vera, 1996: Characteristics of the Southern Hemisphere winter storm track with filtered and unfiltered data. J. Atmos. Sci., 53, 468-481.

Chang, E. K. M., and I. Orlanski, 1994: On energy flux and group velocity of waves in baroclinic flows. J. Atmos. Sci., 51, 38233828.

Charney, J. G., and P. G. Drazin, 1961: Propagation of planetaryscale disturbances from the lower into the upper atmosphere. J. Geophys. Res., 66, 83-109.

Fishbein, E. F., and Coauthors, 1996: Validation of UARS Micro- 
wave Limb Sounder temperature and pressure measurements. J. Geophys. Res., 101, 9983-10 016.

Gan, M. A., and V. B. Rao, 1994: The influence of the Andes Cordillera on transient disturbances. Mon. Wea. Rev., 122, 1141-1157.

Haynes, P., and E. Shuckburgh, 2000: Effective diffusivity as a diagnostic of atmospheric transport. 1. Stratosphere. J. Geophys. Res., 105, 22 777-22 793.

Horel, J. D., 1981: A rotated principal component analysis of the interannual variability of the Northern Hemisphere $500 \mathrm{mb}$ height field. Mon. Wea. Rev., 109, 2080-2092.

Hoskins, B. J., M. E. McIntyre, and A. W. Robertson, 1985: On the use and significance of isentropic potential vorticity maps. Quart. J. Roy. Meteor. Soc., 111, 877-946.

James, I. A., 1994: Introduction to Circulating Atmospheres. Cambridge University Press, $422 \mathrm{pp}$.

Kalnay, E., and Coauthors, 1996: The NCEP/NCAR 40-Year Reanalysis Project. Bull. Amer. Meteor. Soc., 77, 437-471.

Kanamitsu, M., W. Ebisuzaki, J. Woollen, S.-K. Yang, J. J. Hnilo, M. Fiorino, and G. L. Potter, 2002: NCEP-DOE AMIP-II Reanalysis (R-2). Bull. Amer. Meteor. Soc., 83, 1631-1643.

Kistler, R., and Coauthors, 2001: The NCEP-NCAR 50-Year Reanalysis: Monthly means CD-ROM and documentation. Bull. Amer. Meteor. Soc., 82, 247-267.

Lau, K.-M., and P. H. Chan, 1985: Aspects of the 40-50 day oscillation during the northern winter as inferred from outgoing longwave radiation. Mon. Wea. Rev., 113, 1889-1909.

Lim, G.-H., and J. M. Wallace, 1991: Structure and evolution of baroclinic waves as inferred from regression analysis. J. Atmos. Sci., 48, 1718-1731.

McKenna, D. S., R. L. Jones, J. Austin, E. V. Browell, M. P. McCormick, A. J. Krueger, and A. F. Tuck, 1989: Diagnostic studies of the Antarctic vortex during the 1987 airborne Antarctic ozone experiment: Ozone miniholes. J. Geophys. Res., 94, 11 641-11 668

McPeters, R. D., and Coauthors, 1996: Nimbus-7 Total Ozone Mapping Spectrometer (TOMS) data products user's guide. National Oceanic and Atmospheric Administration Reference Publication 1384, 116 pp.

Mote, P. W., J. R. Holton, and J. M. Wallace, 1991: Variability in total ozone associated with baroclinic waves. J. Atmos. Sci., 48, 1900-1903.

O’Lenic, E. A., and R. E. Livezey, 1988: Practical considerations in the use of rotated principal component analysis (RPCA) in diagnostic studies of upper-air height fields. Mon. Wea. Rev., 116, 1682-1689.

Orlanski, I., and J. Katzfey, 1991: The life cycle of a cyclone wave in the Southern Hemisphere. Part I: Eddy energy budget. $J$. Atmos. Sci., 48, 1972-1998.

— velopment over western North America. Mon. Wea. Rev., 121, 2929-2950.

- M. Marino, C. Menendez, and J. Katzfey, 1989: The role of cyclones in the daily variability of Antarctic ozone. Preprints, Third Int. Conf. on Southern Hemisphere Meteorology and Oceanography, Buenos Aires, Argentina, Amer. Meteor. Soc., 116-121.

Orsolini, Y., D. Cariolle, and M. Déqué, 1995: Ridge formation in the lower stratosphere and its influence on ozone transport:
A general circulation model study during late January 1992. J. Geophys. Res., 100, $11113-11135$.

Park, J. H., and Coauthors, 1996: Validation of Halogen Occultation Experiment $\mathrm{CH}_{4}$ measurements from the UARS. J. Geophys. Res., 101, 10 183-10 204.

Perez, A., E. Crino, I. Aguirre de Carcer, and F. Jaque, 2000: Low-ozone events and three-dimensional transport at midlatitudes of South America during springs of 1996 and 1997. J. Geophys. Res., 105, 4553-4561.

Randel, W. J., and J. B. Cobb, 1994: Coherent variations of monthly mean total ozone and lower stratospheric temperature. J. Geophys. Res., 99, 5433-5447.

_, F. Wu, J. M. Russell III, A. Roche, and J. W. Waters, 1998: Seasonal cycles and QBO variations in stratospheric $\mathrm{CH}_{4}$ and $\mathrm{H}_{2} \mathrm{O}$ observed in UARS HALOE data. J. Atmos. Sci., 55, 163-185.

Reed, R. J., and E. F. Danielsen, 1959: Fronts in the vicinity of the tropopause. Arch. Meteor. Geophys. Bioklimatol., 11A, 1-17.

Rood, R. B., J. E. Nielsen, R. S. Stolarski, A. R. Douglass, J. A. Kaye, and D. J. Allen, 1992: Episodic total ozone minima and associated effects on heterogeneous chemistry and lower stratospheric transport. J. Geophys. Res., 97, 7979-7996.

Salby, M. L., and P. F. Callaghan, 1993: Fluctuations of total ozone and their relationship to stratospheric air motions. $J$. Geophys. Res., 98, 2715-2727.

Solomon, S., and R. R. García, 1985: Transport processes and ozone perturbations. J. Geophys. Res., 90, 12 981-12 989.

Stanford, J. L., J. R. Ziemke, R. D. McPeters, A. J. Krueger, and P. K. Barthia, 1995: Spectral analyses, climatology and interannual variability of Nimbus-7 TOMS version 6 total column ozone. National Oceanic and Atmospheric Administration Reference Publication 1360, 80 pp.

Trenberth, K. E., 1991: Storm tracks in the Southern Hemisphere. J. Atmos. Sci., 48, 2159-2178.

Vaughan, G., and J. D. Price, 1991: On the relationship between total ozone and meteorology. Quart. J. Roy. Meteor. Soc., 117, 1281-1298.

Vera, C. S., P. K. Vigliarolo, and E. H. Berbery, 2002: Cold season synoptic-scale waves over subtropical South America. Mon. Wea. Rev., 130, 684-699.

Vigliarolo, P. K., C. S. Vera, and S. B. Díaz, 2001: Southern Hemisphere winter ozone fluctuations. Quart. J. Roy. Meteor. Soc., 127, 559-577.

Waugh, D., and W. Randel, 1999: Climatology of Arctic and Antarctic polar vortices using elliptical diagnostics. J. Atmos. Sci., 56, 1594-1613.

Weare, B. C., and J.S. Nasstrom, 1982: Examples of extended empirical orthogonal function analyses. Mon. Wea. Rev., 110, 481-485.

Wirth, V., 1991: What causes the seasonal cycle of stationary waves in the southern stratosphere? J. Atmos. Sci., 48, 11941200.

, 1993: Quasi-stationary planetary waves in total ozone and their correlation with lower stratospheric temperature. $J$. Geophys. Res., 98, 8873-8882.

Ziemke, J. R., S. Chandra, R. D. McPeters, and P. A. Newman, 1997: Dynamical proxies of column ozone with applications to global trend models. J. Geophys. Res., 102, 6117-6129. 